DOI: https://doi.org/10.24867/05BE10Ninkovic

\title{
LOKALIZACIJA MOBILNIH UREĐAJA U ZATVORENOM PROSTORU POMOĆU MAŠINSKOG UČENJA
}

\section{MACHINE LEARNING - BASED INDOOR LOCALIZATION FOR MOBILE DEVICES}

\author{
Vukan Ninković, Dejan Vukobratović, Dejan Nemec, Fakultet tehničkih nauka, Novi Sad
}

\section{Oblast - ELEKTROTEHNIKA I RAČUNARSTVO}

Kratak sadržaj - Usled velikog napretka u razvoju mobilnih uređaja, problem njihove lokalizacije u zatvorenom prostoru postaje jedna od najvažnijih tema današnjice. Najnovije ideje vezane za njegovo rešavanje su usko povezane sa principima mašinskog učenja. Mi predlažemo novi algoritam, koji posmatra vremensko - frekvencijsku strukturu signala nakon OFDM demodulacije kao sliku, $i$ koristi sve benefite mašinskog učenja koji se već primenjuju u rešavanju problema obrade $i$ klasifikacije slike. Na kraju vršimo poređenje različitih arhitektura po tačnosti klasifikacije $i$ vremenu potrebnom za trening neuralne mreže.

Ključne reči: Lokalizacija u zatvorenom prostoru, mašinsko učenje, klasifikacija, preciznost, kompleksnost, 802.11ah

\begin{abstract}
With the proliferation of mobile devices, indoor localization has become an increasingly important problem. The latest ideas related to its solution are closely related to the principles of machine learning. We propose new algorithm wich considers time - frequency representation of the signal, after OFDM demodulation, as a picture and uses all benefits of machine learning that are alredy applied in solving the problem of image processing and classification. At the end we compare different architectures by accuracy and complexity.
\end{abstract}

Keywords: Indoor localization, machine learning, classification, accuracy, complexity, 802.11ah

\section{UVOD}

Velikim napretkom u razvoju mobilnih uređaja i bežičnih (eng. wireless) tehnologija, servisi koji omogućavaju lokalizaciju u zatvorenim prostorima (npr. unutrašnjosti zgrade) postaju izuzetno važni. Za razliku od GPS (eng. Global Positioning System) sistema koji ostvaruje dobre performanse na otvorenom prostoru, kada postoji vidljivost između predajnika i prijemnika, lokalizacija uređaja u zatvorenom prostoru se susreće sa različitim preprekama i izazovima. Tu se pre svega misli na jako specifično radio okruženje u kom signal propagira, a koje uključuje različite efekte višestruke propagacije, senčenja, fedinga i kašnjenja. Istorijski gledano, postoje tri osnovna predloga za rešenje ovog problema [1]:

\section{NAPOMENA:}

Ovaj rad proistekao je iz master rada čiji mentor je bio dr Dejan Vukobratović, red.prof.
- Ugao dolaska talasa na prijem (eng. Angle of Arrival - AoA) i pravac dolaska talasa na prijem (eng. Direction of Arival - DoA)

- Vreme dolaska talasa (Time of Arrival - ToA), kao i vremenska razlika prispeća dva uzastopna talasa na prijem (eng. Time Difference of Arrival - TDoA)

- Pomoću snage primljenog signala (eng. Received Signal Strength - RSS). Ova tehnika je takođe poznata kao tehnika „otiska“.

Ekspanzijom mašinskog učenja, pojavljuju se autori koji pokušavaju da problem lokalizacije u zatvorenom prostoru reše upravo primenom principa mašinskog učenja, gde se neuralne mreže sve više nameću kao rešenje koje ime značajno bolje rezultate od gore navedenih tehnika. Kao ulaz u neuralnu mrežu, pomenuti autori su uglavnom koristili informacije o stanju kanala (eng. Channel State Information - CSI), tj. informacije koje predstavljaju uticaj kanala na svaki podnosioc OFDM (eng. Orthogonal Frequency-Division Multiplexing) sistema. Dati uticaj se ogleda u promeni amplitude i faze svakog podnosioca prilikom propagacije kroz specifično radio okruženje. Predloženo je nekoliko sistema koji koriste ove podatke, i koji pružaju bolje rezultate od klasičnih pristupa. $\mathrm{Na}$ primer, možemo navesti FIFS sistem koji koristi usrednjene amplitude CSI vrednosti [2], zatim DeepFi [3] i PhaseFi [4] koji koriste amplitude CSI vrednosti $i$ podatke o fazi CSI, respektivno.

Takođe, postoje i hibridni modeli, koji pokušavaju da iskoriste kombinaciju starijih predloga (AoA, ToA) sa informacijom koju dobijamo pomoću CSI, i tu se izdvaja ResLoc algoritam [5].

Iako postoje značajna poboljšanja, rezultati koje postižu gore navedeni algoritmi još uvek nisu prihvatljivi. Zbog toga, naš pristup se prilično razlikuje od svih navedenih, kako po podacima koje koristimo u samoj neuralnoj mreži, tako i po činjenici da svi navedeni algoritmi pretpostavljaju da se određivanje lokacije vrši na samom mobilnom uređaju, što sa sobom nosi zahteve smanjene kompleksnosti i brzog izvršavanja. Naša pretpostavka je da bazna stanica određuje lokaciju, što značajno smanjuje potrošnju mobilnog uređaja. Takođe, na ulaz neuralne mreže dovodimo "sirove", tj. neobrađene podatke sa fizičkog sloja, koje u daljoj obradi posmatramo kao sliku, i primenjujemo neuralne mreže koje su se već dokazale $u$ problemima obrade i klasifikacije slike. 
Poglavlje 2 opisuje model sistema (struktura ulaznih podataka i implementacija algoritma), poglavlje 3 govori o korišćenim arhitekturama neuralnih mreža, poglavlje 4 sadrži evaluaciju predloženog sistema, a poglavlje 5 predstavlja zaključak rada.

\section{MODEL SISTEMA}

\subsection{Preambula 802.11ah paketa}

Podaci korišćeni u ovom istraživanju su dobijeni simulacijom paketa specifičnog WiFi standarda 802.11ah (WiFi HaLow) u realnom okruženju (kancelarijski prostor). Ovaj standard je razvijen od strane IEEE tokom 2016. i 2017. godine, i osnovni cilj mu je da podrži širok spektar IoT (eng. Internet of Things) funkcionalnosti. WiFi HaLow funkcioniše $\mathrm{u}$ frekvencijskom opsegu ispod $1 \mathrm{GHz}$ (oko $900 \mathrm{MHz}$ ), a njegov domet je dva puta veći u poređenju sa svim prethodnim $\mathrm{WiFi}$ standardima, tj. oko $1.5 \mathrm{~km}$. Takođe, omogućava konektovanje velikog broja uređaja uz značajno redukovanu potrošnju energije. Naravno, povećanje dometa je uslovilo smanjenje brzine protoka, koja u ovom standardu iznosi od $150 \mathrm{kbps}$ do $346 \mathrm{Mbps}$ [6].

Svaki 802.11 ah paket zauzima $2 \mathrm{MHz}$ i ima identičnu strukturu koja se sastoji od preambule i dela koji nosi podatke. Strukturu preambule možemo videti na slici 1:

\begin{tabular}{|c|c|c|}
\hline $\begin{array}{c}\text { Short } \\
\text { Training } \\
\text { Field }\end{array}$ & $\begin{array}{l}\text { Long } \\
\text { Training } \\
\text { Field }\end{array}$ & $\begin{array}{l}\text { Signal } \\
\text { Field }\end{array}$ \\
\hline
\end{tabular}

Slika 1. Struktura 802.11ah preambule [6]

Tri osnovna polja svake preambule su (slika 1.) [6]:

- $\quad$ STF (eng. Short Training Field) koje se sastoji od 2 OFDM simbola, i služi za detekciju paketa i inicijalnu estimaciju frekvencijskog pomeraja.

- LTF (eng. Long Training Field) koje se takođe sastoji od 2 OFDM simbola i služi za finu estimaciju frekvencijskog pomeraja, ali i za procenu kanala na prijemu.

- $\quad$ SIG (eng. Signal Field ) koje se sastoji od 2 OFDM simbola i sadrži informacije za konfigurciju prijemnika (tip korišćene modulacije, tip kodovanja, količina prenesenih podataka)

Svaki OFDM simbol sadrži 56 korisnih podnosioca, pri čemu 52 podnosioca služe za prenos informacije od predajnika ka prijemniku (4 podnosioca služe kao piloti).

\subsection{Struktura ulaznih podataka}

Kako se ne bi zauzimao dodatni propusni opseg kanala (prenošenjem nezavisne informacije koja bi mogla da nam ukaže na lokaciju mobilnog uređaja), ideja je da se iskoristi preambula koja se prenosi u sklopu svakog 802.11ah paketa. U posmatranom scenariju mobilni uređaj (tj. predajnik) uvek šalje fiksnu preambulu, i na taj način dolazi do značajnog smanjenja kompleksnosti predajnika (kao i minimizovanja utrošene energije). Na putu od predajnika ka prijemniku svaka preambula će doživeti različite distorzije (usled uslova propagacije), a što je prijemnik udaljeniji, slabljenje će biti veće.

$\mathrm{Na}$ strani prijemnika smo posmatrali LTF polje preambule, koje u suštini predstavlja matricu veličine $56 \times 2$ (posmatramo podnosioce koji nose informaciju i pilote). Ta matrica se dovodi na ulaz neuralne mreže, i dalje obrađuje kao slika, a vrednost jednog podnosioca $u$ jednom OFDM simbolu predstavlja jedan piksel date „slike“. Naravno, s obzirom da su primljene vrednosti podnosioca kompleksne, na prijemu se prvo mora izračunati njihova amplituda, kako bi mogla biti primenjena odgovarajuća neuralna mreža.

LTF polje jednog primljenog paketa možemo videti na slici 2:

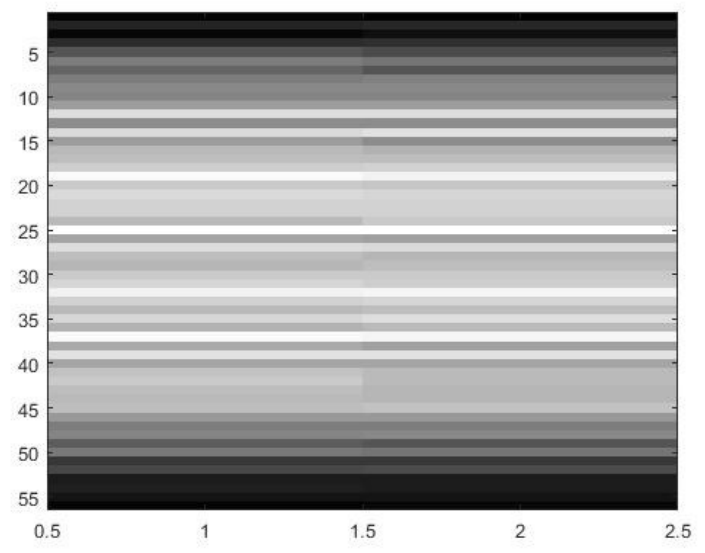

Slika 2. LTF polje preambule primljenog paketa

\subsection{Implementacija algoritma}

Set podataka je formiran tako što smo sa svake od 13 različitih pozicija poslali po 1000 fiksnih preambula 802.11ah paketa, i na prijemu izdvajali LTF polje. Dato polje predstavlja ulaz u neuralnu mrežu, tj. neuralna mreža se trenira na slikama veličine $56 \times 2$. Merenja su izvršena u kancelarijskom prostoru veličine $5.5 \mathrm{mx} 3,5 \mathrm{~m}$, pri čemu su i predajnik (mobilni uređaj) i prijemnik (bazna stanica) smešteni $u$ istoj prostoriji. Bitno je napomenuti da je pozicija prijemnika fiksna, dok se predajnik pomera kao što je prikazano na slici 3. Razmak između susednih pozicija je bio $0.7 \mathrm{~m}$ i po horizontali i po vertikali, a predajnik i prijemnik su bili na istoj visini, tako da smo problem posmatrali u dve dimenzije.

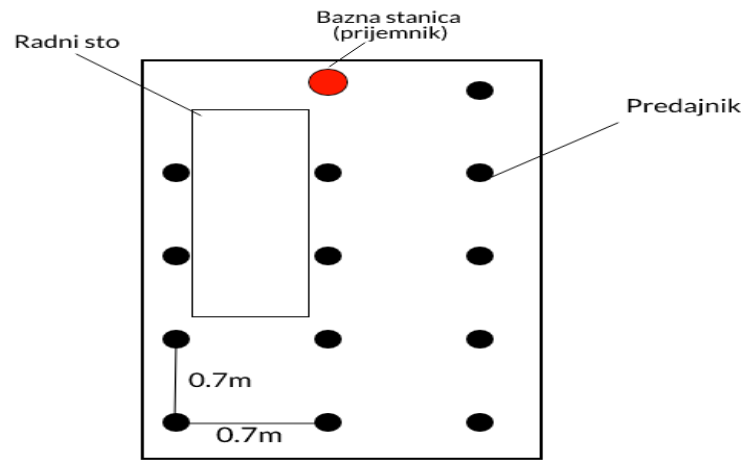

Slika 3. Položaji predajnika (crni krugovi) i prijemnika (crveni krug) unutar kancelarijskog prostora 
Glavna pretpostavka na kojoj se bazira naš rad je da sa promenom pozicije predajnika dolazi do promene propagacionog okruženja, i samim tim do promene vrednosti amplitude primljene preambule. Sa svake pozicije mi smo imali jednu matricu veličine 56x2000 koju smo u pretprocesiranju morali da ,isečemo“ na 1000 slika veličine $56 \times 2$. Važno je reći da su se vrednosti amplitude LTF polja kretale u opsegu od 0.001 do 0.3 , pa nije bilo potrebe za dodatnom normalizacijom podataka. Dobijene slike se čuvaju kao bin fajlovi, i ti fajlovi se dovode na ulaz neuralne mreže. Ovaj postupak se ponavlja za svaku poziciju.

\section{ARHITEKTURA NEURALNE MREŽE}

Jedan od najvažnijih parametara, koji ima značajan uticaj na performanse i kompleksnost sistema, predstavlja arhitektura neuralne mreže. Problem lokalizacije u zatvorenim prostorima, u našoj interpretaciji, može se posmatrati kao problem klasifikacije slike. Upravo zbog toga $\mathrm{u}$ datom istraživanju korišćene su dve arhitekture koje su pokazale zavidne rezultate prilikom rešavanja različitih vrsta problema u obradi i klasifikaciji slike. To su:

\section{- $\quad$ AlexNet [7]}

- $\operatorname{ResNet~[8]}$

Obe arhitekture predstavljaju konvolucione neuralne mreže, prilagođene konkretnom problemu i podacima kojima raspolažemo.

\subsection{AlexNet}

Originalnu AlexNet arhitekturu možemo videti na slici 4:

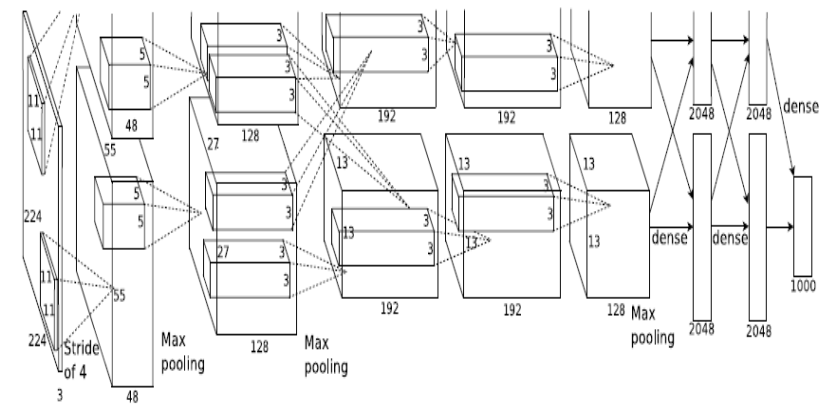

Slika 4. Originalna AlexNet arhitektura

Prvi konvolucioni sloj filtrira ulaznu sliku veličine $52 \times 2$ sa 32 kernela veličine $2 \times 2 \times 1$, pri čemu je korak jedan piksel. Drugi konvolucioni sloj kao ulaz uzima izlaz prvog konvolucionog sloja i filtrira ga sa 64 kernela veličine $2 \times 2 \times 32$, korak je takođe jedan piksel. Treći konvolucioni sloj sadrži 128 kernela veličine $2 \times 2 \times 64$, četvrti konvolucioni sloj ima 256 kernela veličine $2 \times 2 \times 128$, a peti konvolucioni sloj ima 128 kernela veličine $1 \times 1 \times 256$. Nakon konvolucionih slojeva slede tri FC (eng. Fully Connected) sloja, pri čemu svaki FC sloj sadrži po 1024 neurona, a izlaz poslednjeg sloja predstavlja SOFTMAX aktivaciona funkcija veličine 13, koja nam prikazuje raspodelu verovatnoća po 13 različitih klasa (klasi sa najvećom verovatnoćom pripada data slika). U svim ostalim slojevima koristi se ReLu aktivaciona funkcija i korak je jedan piksel.

\subsection{ResNet}

ResNet arhitektura predstavlja arhitekturu koja omogućava lakše treniranje značajno dubljih neuralnih mreža, pomoću rezidualnog učenja. Osnovni blok rezidualnog učenja možemo videti na slici 5:

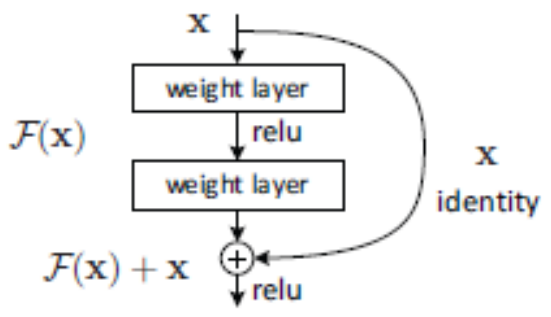

\section{Slika 5. Osnovni blok rezidualnog učenja}

Arhitektura mreže koju smo koristili je identična kao originalna ResNet arhitektura [8]. Jedina razlika je veličina filtra koja je svuda $2 \times 2$ (umesto $3 \times 3$ ). Aktivaciona funkcija je ReLu za sve slojeve sem poslednjeg (FC sloja), gde opet primenjujemo SOFTMAX funkciju.

\subsection{Arhitekture smanjene kompleksnosti}

Predložene arhitekture imaju jedan nedostatak, a to je velika kompleksnost. Kako bi izbegli ovaj problem pokušali smo da napravimo što jednostavniji model, koji bi imao najbolji odnos performansi i utrošene energije. Ispostavilo se da arhitekture sa dva konvoluciona i jednim FC slojem ili sa tri FC sloja daju rezultate koji se u potpunosti mogu meriti sa rezultatima značajno kompleksnijih algoritama, a poređenje predloženih algoritama sledi u narednom poglavlju.

\section{REZULTATI EKSPERIMENTA}

Dobijeni skup podataka, koji se sastoji od 1000 slika veličine $56 \times 2$ za svaku od 13 klasa se na samom početku deli, tako da se $70 \%$ skupa koristi za trening, 20\% skupa za validaciju i $10 \%$ skupa za test. Test skup nema nikakvih dodirnih tačaka sa procesom treninga, i on se koristi samo za proveru istrenirane mreže. Cilj je dobiti mrežu koja ima najbolji odnos performansi i kompleksnosti, pri čemu smo za kompleksnost mreže uzimali vreme koje je potrebno mreži da iskonvergira, $\mathrm{tj}$. da završi proces treninga. Za sve eksperimente početna brzina učenja je bila $10^{-2}$ i data brzina se smanjivala za red veličine kada funkcija greške uđe u zasićenje. Treninzi različitih arhitektura neuralne mreže rađeni su pod identičnim uslovima (sa po 100 epoha) kako bi ih mogli uporediti po performansama i kompleksnosti, što možemo videti na slikama 6 i 7 .

Sa slike 6 možemo videti da najbolju tačnost klasifikacije na test skupu od 100 slika ima ResNet arhitektura (83.7\%) ali ova arhitektura ima ubedljivo najduži period treninga od čak 302 minuta (slika 7). Takođe, zbog dubine ove arhitekture, vrlo čest problem je preveliko prilagođavanje mreže trening skupu (eng. overfitting). Na drugom mestu i po preciznosti i po vremenu treninga se nalazi AlexNet (81.3\% i 160 minuta). Treće mesto zauzima mreža koja se sastoji od 3 FC sloja sa preciznošću $80.5 \%$ i vremenom treninga od 101 minuta. 


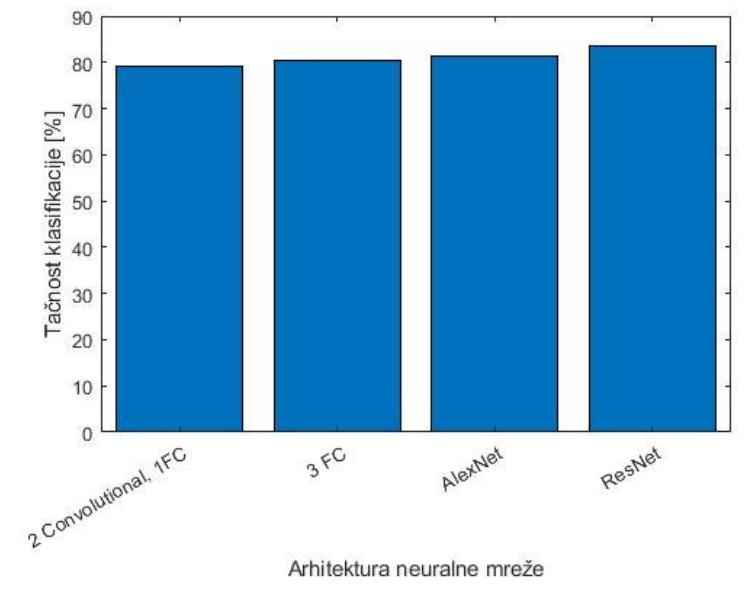

Slika 6. Tačnost klasifikacije različitih arhitektura neuralne mreže

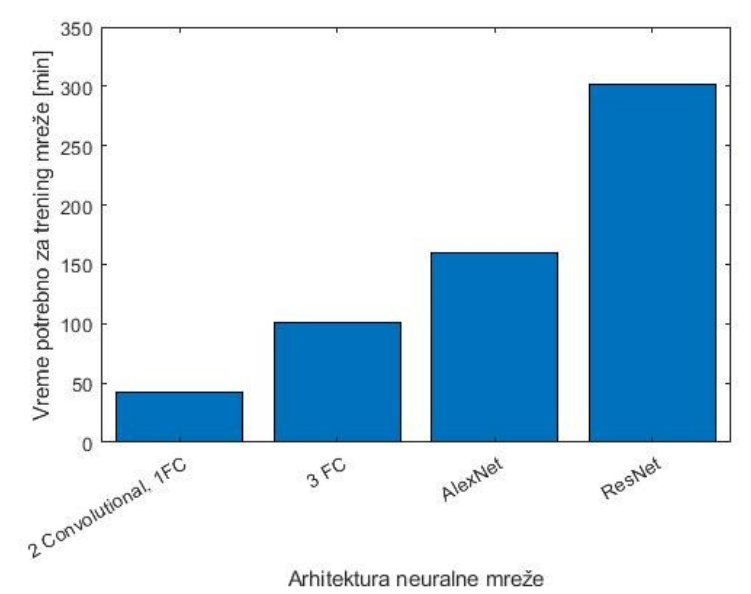

Slika 7. Kompleksnost različitih arhitektura neuralne mreže (vreme potrebno za konvergenciju)

$\mathrm{Na}$ poslednjem mestu, ali sa ubedljivo najmanjim vremenom potrebnim za trening mreže nalazi se arhitektura koja se sastoji od dva konvoluciona i jednog FC sloja (79.2\% i 42 minuta). Lako je uočljivo da se tačnost različitih arhitektura razlikuje za vrlo mali procenat, tj od $2 \%$ do $3 \%$. Sa druge strane primetna je jako velika razlika u vremenu potrebnom za trening različitih arhitektura, koja u ekstremnom slučaju ide i do 260 minuta, tj. više od 4 sata. Jasno je da je kompleksnost mreže karakteristika o kojoj u praktičnim primenama moramo voditi najviše računa.

\section{ZAKLJUČAK}

Primena principa mašinskog učenja za rešavanje problema komunikacionih sistemima predstavlja trend koji se u poslednjih godinu dana sve više razvija. Svakog dana pojavljuju se novi algoritmi koji postižu bolje performanse $\mathrm{u}$ odnosu na klasične $\mathrm{i}$ konvencionalne algoritme. U ovom radu smo predstavili potpuno nov pristup za rešavanje problema lokalizacije uređaja $u$ zatvorenim prostorima, koji se oslanja na "sirove“ podatke sa fizičkog sloja, i ne zahteva prenos dodatne informacije od predajnika ka prijemniku. Takođe, dati algoritam koristi sve prednosti neuralnih mreža koje su otkrivene $\mathrm{u}$ rešavanju problema obrade i klasifikacije slike. Uporedili smo nekoliko klasičnih arhitektura neuralnih mreža, i zaključili da postoji velika razlika u njihovoj kompleksnost. Preciznost klasifikacije, koja je oko $80 \%$, još uvek nije u potpunosti zadovoljavajuća, ali daje dobru osnovu za dalji rad i istraživanje ove teme.

\section{LITERATURA}

[1] A. Khalajmehrabadi, N. Gatsis, D. Akopian "Modern WLAN Fingerprinting Indoor Positioning Methods and Deployment Challenges", IEEE Commun. Surv. Tutor., 2017.

[2] J. Xiao, K. Wu, Y. Yi, L. Ni , "FIFS: Fine-grained indoor fingerprinting system", Proc. IEEE ICCCN'12, pp. 1-7, August 2012.

[3] X. Wang, L. Gao, S. Mao, S. Pandey, "CSI-based fingerprinting for indoor localization: A deep learning approach", IEEE Trans. Veh. Technol., vol. 66, no. 1, pp. 763-776, January 2017.

[4] X. Wang, L. Gao, S. Mao, "CSI phase fingerprinting for indoor localization with a deep learning approach", IEEE Internet of Things J., vol. 3, no. 6, pp. 11131123, December 2016.

[5] X. Wang, S. Mao, "ResLoc: Deep Residual Sharing Learning for Indoor Localizaton with CSI Tensors", Proc. IEEE PIMRC'17, pp. 1-7, October 2017.

[6] E.Perahia, R.Stacey, "Next Generation Wireless LANs: Throughput, Robustness, and Reliability in 802.11n", Cambridge, 2008.

[7] A. Krizhevsky, I. Sutskever, G. Hinton, "Imagenet classification with deep convolutional neural networks", Advances in neural information processing system, pp. 1097-1105, 2012.

[8] K. He, X. Zhang, S. Ren, J.Sun "Deep residual learning for image recognition", Proc. of CVPR, pp. 770-778, 2016.

\section{Kratka biografija:}

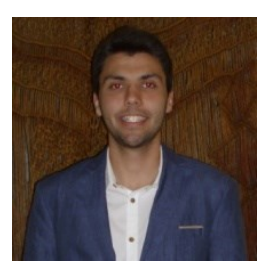

Vukan Ninković rođen je u Šapcu 1995. god. Master rad na Fakultetu tehničkih nauka iz oblasti Elektrotehnike i računarstva - Komunikacione tehnologije i obrada signala odbranio je 2019.god. kontakt: vukan.ninkovic@gmail.com

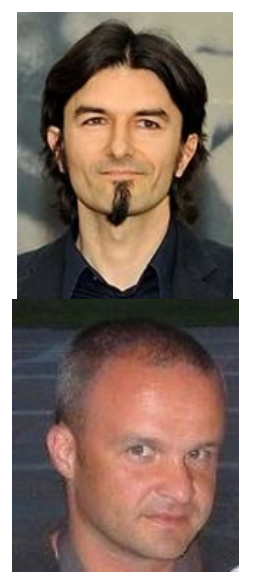

Dejan Vukobratović doktorirao je na Fakultetu tehničkih nauka 2008. god., a od 2019. je u zvanju redovni profesor. Oblast interesovanja je Teorija informacija i komunokacija.

Dejan Nemec rođen je 1972. god. Diplomirao, specijalizirao i magistrirao je na Fakultetu tehničkih nauka iz oblasti Elektrotehnike i računarstva. Oblast interesovanja su telekomunikacije i obrada signala. 